\title{
Nephrogenic adenoma of the bladder: a case report
}

\section{Mesanenin nefrojenik adenomu: olgu sunumu}

\author{
Samet Şenel ${ }^{1}$, Cevdet Serkan Gökkaya ${ }^{1}$, Serra Kayaçetin ${ }^{2}$, Süleyman Bulut ${ }^{1}$ \\ ${ }^{1}$ Sağlık Bilimleri Üniversitesi, Ankara Numune Eğitim ve Araştırma Hastanesi, Üroloji Kliniği, Ankara \\ ${ }^{2}$ Sağlık Bilimleri Üniversitesi, Ankara Numune Eğitim ve Araştırma Hastanesi, Patoloji Kliniği, Ankara
}

Dergiye Ulaşma Tarihi: 19.09.2018 Dergiye Kabul Tarihi: 23.10.2018 Doi: 10.5505/aot.2019.66487

\section{ÖZET}

Nefrojenik adenom, üreteryal mukozanın nadir benign bir lezyonudur. Bizim olgumuz mesanede insidental olarak saptanan, bilateral hidronefrozun eşlik ettiği nefrojenik adenom olgusudur. 59 yaşında kadın hasta. Sistoskopide mesane karşı duvarda $1 \mathrm{~cm}$ boyutunda şüpheli papiller lezyon izlendi ve transüretral rezeksiyon uygulandi. Patoloji sonucu nefrojenik adenom (nefrojenik metaplazi) olarak raporlandi. Nefrojenik adenom \%68.6 ile en çok mesanede görülürken üretra(\%13.3), üreter(\%8.2), renal pelvis( $\% 8.2)$ ve nadiren de prostatta $(\% 2)$ görülebilmektedir. Nefrojenik adenomlar, kronik iritasyon veya idrar yolunun inflamasyonu ile güçlü bir şekilde ilişsilidir. İmmünohistokimyasal olarak diğer malign lezyonlardan ayrımı yapılmalıdır. Eşlik edebileceği malign lezyonlardan ve rekürrens açısından takip edilmelidir.

Anahtar Kelimeler: mesane, nefrojenik adenom, nefrojenik metaplazi

\begin{abstract}
Nephrogenic adenoma is a rare benign lesion of urothelial mucosa. Our case is an incidentally detected nephrogenic adenoma accompanied by bilateral hydronephrosis. A 59-year-old female. At cystoscopy, suspicious papillary lesion measuring $1 \mathrm{~cm}$ was observed on anteior wall of the bladder and transurethral resection was performed.Pathologically, the result was reported as nephrogenic adenoma (nephrogenic metaplasia). The urinary bladder is the most common location of nephrogenic adenom (68.6\%)and it is followed by the urethra (13.5\%),ureter (8.2\%), renal pelvis $(8.2 \%)$ and prostate $(2 \%)$. Nephrogenic adenomas are strongly associated with chronic irritation or inflammation of the urinary tract. Other malign lesions should be distinguished immunohistochemically and histopathologically. It should be followed for concomitant malignant lesions and frequent local recurrences.
\end{abstract}

Keywords: urinary bladder, nephrogenic adenoma, nephrogenic metaplasia

\section{GİRIŞ}

Nefrojenik adenom, üretelyall mukozanın nadir benign bir lezyonudur (1,2). 1950 y1lında, Fiedman ve Kuhlenbeck tarafindan histolojik yapısının renal tubullere benzerliğinden dolayı 'nefrojenik adenom' olarak adlandırılmıştır (3). Nefrojenik adenom \% 68.6 ile en çok mesanede görülürken üretra( $\%$ 13.3), üreter $(\% 8.2)$, renal pelvis $(\%$ 8.2) ve nadiren de prostatta $(\% 2)$ görülebilmektedir (4). Nefrojenik adenom için predispozan faktörler genitoüriner travma, geçirilmiş cerrahi, kronik inflamasyon, renal kalkül, tekrarlayan enstrumantasyon, anatomik anomali, pelvik radyasyon maruziyeti ve ibuprofen, fenasetin gibi bazı ilaçların kullanımıdır (5). Nefrojenik adenomlu hastaların klinik bulguları arasında hematüri, alt üriner sistem semptomları, pelvik veya flank ağrısı, hidronefroz ve üriner inkontinans yer alır (6). 
Bizim olgumuz mesanede insidental olarak saptanan, bilateral hidronefrozun eşlik ettiği nefrojenik adenom olgusudur.

\section{OLGU SUNUMU}

59 yaşında kadın hasta, bilateral yan ağrısı ve s1k tekrarlayan üriner sistem enfeksiyonu şikayeti ile kliniğimize başvurdu. Hastaya yapılan tetkiklerde serum kreatin $2.46 \mathrm{mg} / \mathrm{dl}$ saptandı. Hastaya çekilen tüm abdomen taş protokol bilgisayarlı tomografide bilateral üreterohidronefroz ve sağ üreterovezikal bileşkede $13 \times 11 \mathrm{~mm}$ taş saptand. Hasta yatırilarak bilateral nefrostomi kateteri takıldi. Ardından hastaya sağ üreterolitotripsi + sol üreterorenoskopi + bilateral DJ kateter takılması uygulandı. Bilateral üreter orifislerinin daralmış olduğu izlendi ve bilateral üreterler dilate saptandı. Aynı işlem sırasında mesane karşı duvarda $1 \mathrm{~cm}$ boyutunda şüpheli papiller lezyon izlendi ve transüretral rezeksiyon uygulandi.

Patolojik makroskopik incelemede $0,6 \times 0,3 \times 0,1$ $\mathrm{cm}$ ölçülerinde kirli beyaz kahverengi 1 adet doku parçası izlendi.

İmmünohistokimyasal incelemede

PanCK, CK7, EMA ve AMACR ile eozinofilik küboidal epitel hücrelerinde boyanma izlendi. CD34 ile damarlarda boyanma izlendi (Şekil 2). PAS boyamasinda luminal musin pozitif görüldü. Sonuç nefrojenik adenom (nefrojenik metaplazi) olarak raporland1.

Hastaya 3. ayda yapilan kontrol sistoskopide alınan punch biyopsi patoloji sonucu, aktif kronik inflamasyon bulguları olarak raporlandı. Eş zamanlı bilateral DJ kateterler çekildi. 2 y 11 llk kontrol sistoskopilerde mesanede yeni lezyon saptanmad 1
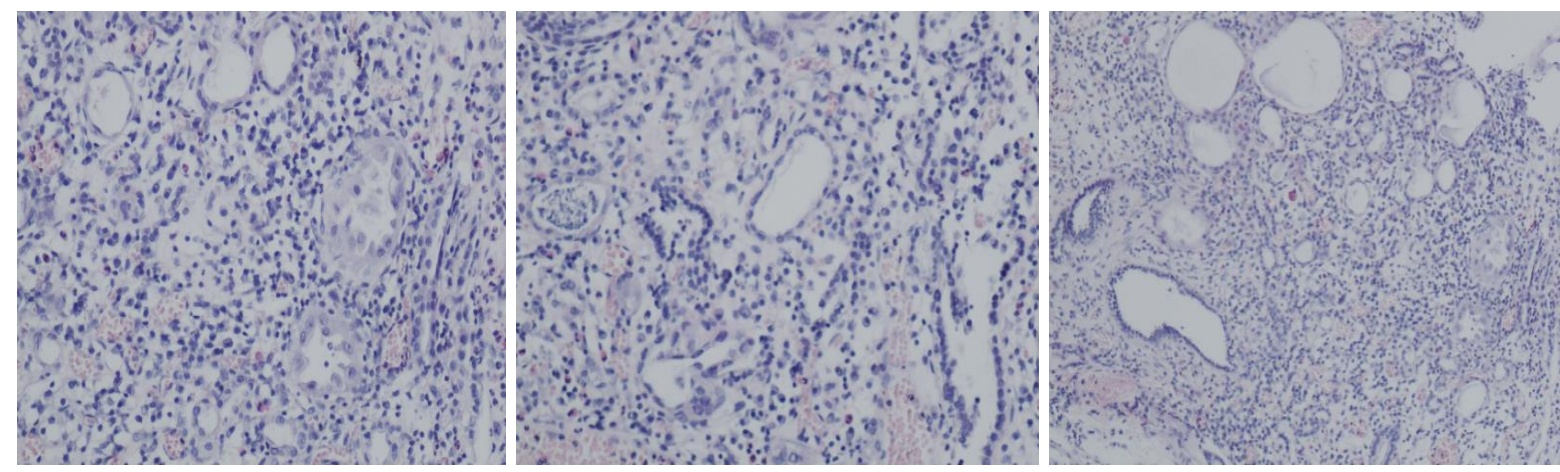

Resim 1. Düz epitel hücrelerinin kan damarı benzeri tubuler yapılardaki tek sıralı dizilimi görülmektedir. Kümelenmiş tübüller adenomatöz lamina propriada gelişigüzel dağılmıştır.
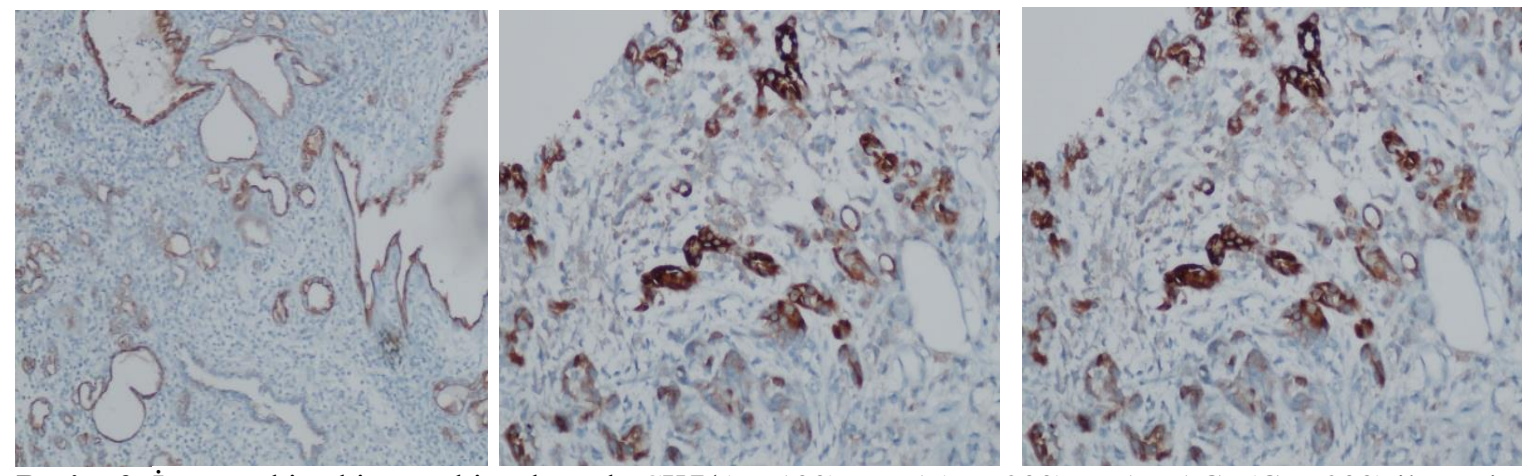

Resim 2. İmmünohistokimyasal incelemede CK7(A,X100), EMA(B,X200) ve AMACR(C, X200) ile eozinofilik küboidal epitel hücrelerinde pozitif boyanma görülmektedir. 


\section{TARTIŞMA}

Nefrojenik adenom ilk olarak 1948 yılında Davis tarafindan tanımlanmıştır (5). 1950 yılında, Fiedman ve Kuhlenbeck tarafindan histolojik yapısının renal tubullere benzerliğinden dolayı 'nefrojenik adenom' olarak adlandırılmıştır (3).

Nefrojenik adenom, üriner sistem mukozasında seyrek görülen benign bir metaplazidir (7). Ancak özellikle bağışıklık sistemi baskılanmış hastalarda premalign bir hastalığ 1 düşündüren, malign dönüşümler bildirilmiştir (8). Her yaşta görülmekle birlikte 4.-6. dekadda daha s1k izlenir. Erkeklerde 2:1 oranında daha sık görülür (9).

Nefrojenik adenomun patogeneziyle ilgili embriyolojik ve inflamatuar teori olmak üzere iki temel teori ileri sürülmüştür. Embriyolojik teori trigon dışında yerleşim gösteren lezyonlar için açıklayıcı değildir. Bununla birlikte kronik inflamasyon veya irritasyona ürotelyumun verdiği metaplastik yanit olarak tanımlanan inflamatuar teori geçerliliğini korumaktadır (10). Ayrıca nefrojenik adenomlar, kronik iritasyon veya idrar yolunun inflamasyonu ile güçlü bir şekilde ilişkilidir. Diğer nedenler arasında, geçirilmiş sistoskopi, mesane cerrahisi, mesane augmentasyonu öyküsü, kronik kateterizasyon, kronik idrar yolu enfeksiyonu, ürolitiazis, intravezikal tedavi (BCG veya mitomisin) ve üretral divertikül bulunur (1). Bizim olgumuzda da ikinci teoriyi destekler nitelikte hastanın tekrarlayan idrar yolu enfeksiyonu öyküsü vardı. Ayrıca kontrol sistoskopide alınan biyopsi örneği aktif kronik inflamasyonla uyumlu olarak raporlanmıştı.

Sistoskopik muayenede genellikle papiller veya polipoid olan soliter veya multipl lezyonlara rastlanır ancak düz olabilirler veya diğer ürotelyal lezyonlar tarafindan gizlenmiş olabilirler (11). Bizim olgumuzda $1 \mathrm{~cm}$ boyutunda papiller lezyon mevcuttu. Bu sebeple üretelyal kanserlerle karışabilmektedir. Nefrojenik adenomun kesin tanısı, biyopsi ve histolojik inceleme sonucu olan patolojik analize dayanmaktadır (2).

Patolojik olarak lezyon yüzeyde papiller projeksiyonları döşeyen ve lamina propriada yer yer ödemli, stromada tubulus benzeri yapılar oluşturan, nukleolü belirgin olmayan berrak veya eozinofilik sitoplazmalı kübik veya hobnail hücrelerden oluşur. Tubuluslar çevresinde kalın ve hyalinize bazal membran bulunur (12). Nefrojenik adenomun epitelyal hücrelerinin renal tubullerdeki epitelyal hücrelere benzerlik gösterdiği ve immünohistokimyasal olarak PAX2, PAX8, AMACR ve CK7 ekspresyonu yaptığ gösterilmiştir (2). Bizim olgumuzda da AMACR ve CK7 ekspresyonu saptand1.

Nefrojenik adenomun mesane değişici epitel hücreli karsinom, skuamöz hücreli karsinom ve adenokarsinomu ile ilişkisi bildirilmiş, karsinoma eşlik eden inflamasyonun nefrojenik adenom gelişimini tetikleyebileceği düşünülmüştür. Bunun yanı sıra, benign olmasına karşın lokal rekürrens eğilimi de olması nedeniyle sistoskopi ile takip önerilmektedir (13). Biz de olgumuzu bu amaçla 2 yıl boyunca sistoskopik olarak takip ettik ve malign transformasyona rastlamadik.

Sonuç olarak nefrojenik adenom, mesanenin nadir görülen benign bir lezyonudur. Buna karşın immünohistokimyasal olarak diğer malign lezyonlardan ayrımı yapılmalıdır. Eşlik edebileceği malign lezyonlar ve rekürrens açısından takip edilmelidir.

\section{Çıkar Çatışması: Yok}

\section{KAYNAKLAR}

1. Amin W, Parwani AV. Nephrogenic adenoma. Pathol Res Pract. 2010;206:659-662.

2. Alexiev BA, LeVea CM. Nephrogenic Adenoma of the urinary tract: A review. Int J Surg Pathol

3. Friedman NB, Kuhlenbeck H. Adenomatoid tumors of the bladder reproducing renal structures (nephrogenic adenomas) J Urol. 1950;64:657-670.

4. López JI, Schiavo-Lena M, Corominas-Cishek A, et all. Nephrogenic adenoma of the urinary tract: Clinical, histological, and immunohistochemical characteristics. VirchowsArch. 2013;463:819-825.

5. Davis TA. Hamartoma of the urinary bladder. Northwest Med 1949;48: 182-5.

6. Gordetsky J, Gennaro KH, Selph JP, Rais-Bahrami S. Nephrogenic Adenoma: Clinical Features, Management, and Diagnostic Pitfalls Urology. 2016 Sep;95:29-33

7. Boscolo-Berto R. Clinical testing and evidencebased medicine: when the absence of evidence doesn't mean evidence of absence [in Italian] G Ital Nefrol. 2009;26:417. 
8. Hungerhuber E, Bach E, Hartmann A, Frimberger D, Stief C, Zaak D. Adenocarcinoma of the bladder following nephrogenic adenoma: a case report. J Med Case Reports. 2008; 2:164.

9. Oliva E, Young RH. Nephrogenic adenoma of the urinary tract: a review of the microscopic appearance of 80 cases with emphasis on unusual features. Mod Pathol 1995;8:722-730

10. Kaswick JA, Waisman J, Goodwin WE. Nephrogenic metaplasia (adenomatoid tumors) of the bladder. Urology 1976;8:283-286
11. Peeker R., Aldenborg F., and Fall M.: Nephrogenic adenoma - a study with special reference to clinical presentation. Br J Urol 1997; 80: pp. 539-542

12. Reuter VE, Mills SE, Carter D: The urothelial tract: renal pelvis ureter urinary bladder and urethra. Diagnostic Surgical Pathology (4th Ed )

13. McIntire TL, Soloway MS, Murphy WM. Nephrogenic adenoma. Urology 1987;29: 237-241 